\title{
Fenomena Lokal "Mata Dwiwarna” di Tinambung Polewali Mandar
}

\author{
Firdaus*1, Mufti Hatur Rahmah², Masyitha Wahid \\ ${ }^{1,2}$ Pendidikan Biologi, FKIP, Universitas Sulawesi Barat \\ e-mail: *11 firdaus@ unsulbar.ac.id, ${ }^{2}$ muftihaturrahmah@unsulbar.ac.id, ${ }^{3}$ masyithawahid@ unsulbar.ac.id
}

\begin{abstract}
Abstrak
Fenomena "mata dwiwarna" atau yang dikenal dengan istilah Heterochromia Iridis merupakan kelainan genetik berupa adanya dua warna pada iris mata suatu individu. Heterochromia Iridis termasuk fenomena langka dengan prevalensi 6:1.000 di dunia. Penelitian ini merupakan deskriptif kualitatif dengan desain penelitian studi kasus untuk mengungkap: (1) karakteristik mata dwiwarna di Tinambung Polewali Mandar dan (2) fenotip penyerta mata dwiwarna di Tinambung Polewali Mandar. Pengumpulan data dilakukan melalui observasi dan wawancara. Hasil penelitian mengungkap dua kasus mata dwiwarna (Heterochromia Iridis) di Tinambung Polewali Mandar. Kasus I memiliki mata kanan yang berwarna biru terang dan mata kiri berwarna coklat tua, termasuk ke dalam tipe Complete Heterochromia. Kasus II memiliki mata yang bagian tengahnya berwarna coklat dan bagian tepinya berwarna biru, termasuk ke dalam tipe Central Heterochromia. Fenotip penyerta yang ditemukan yaitu alis mata bersambung, pangkal hidung lebar, ujung hidung yang rata, bercak putih pada kulit, gangguan pendengaran, dan rambut putih di usia muda. Fenotip penyerta tersebut menunjukkan bahwa fenomena mata dwiwarna di Tinambung Polewali Mandar terasosiasi dengan Waardenburg Syndrome. Hasil penelitian ini dapat dijadikan dasar dalam penanganan fenomena lokal "mata dwiwarna" dan sebagai bahan dalam pembuatan media ajar kontekstual.
\end{abstract}

Kata Kunci: Fenomena Lokal, Heterochromia Iridis, Mata Dwiwarna, Waardenburg Syndrome.

\section{PENDAHULUAN}

Mata dwiwarna atau Heterochromia Iridis didefinisikan sebagai variasi pada iris mata dari sisi warna maupun strukturnya. Fenomena ini telah ada pada masa lampau. Dalam catatan sejarah, Kaisar Byzantine Anastasius I memiliki julukan "Dicorus" karena salah satu matanya berwarna hitam dan lainnya berwarna biru. Sementara Alexander the Great juga memiliki warna mata yang berbeda yaitu hazel dan hijau, Aristoteles menyebutnya sebagai heterotalus (Gladstone, 1969) Heterochromia Iridis termasuk fenomena langka dengan prevalensi 6:1.000 di dunia (Dahl, 2020)

Variasi warna pada mata ditentukan oleh konsentrasi dan distribusi pigmen melanin pada iris. Individu dengan Heterochromia Iridis memiliki iris yang hypochromic atau hyperchromic. Fenomena ini dapat disebabkan oleh mutasi yang terjadi pada gen-gen yang mengatur distribusi melanin pada jalur hydroxy tryptophan (8-HTP) (Díez et al., 2015). Selain itu, faktor lingkungan juga mempengaruhi konsentrasi dan distribusi melanin pada iris. Individu yang tinggal di daerah yang dekat dengan ekuator dimana intensitas radiasi ultra violetnya (UVR) tinggi, umumnya memiliki kulit, rambut, dan warna mata yang lebih gelap sebagai mekanisme pertahanan terhadap dampak berbahaya UVR. Sebaliknya, individu yang tinggal di daerah yang jauh dari ekuator dimana intensitas radiasi ultra violetnya (UVR) rendah, cenderung memiliki kulit, rambut, dan warna mata yang lebih cerah untuk memfasilitasi produksi vitamin D (Mackey et al., 2011).

Iris mata pada manusia umumnya berwarna biru, hazel, atau cokelat (Díaz et al., 2009) Kemudian (Mackey et al., 2011) melaporkan warna intermediet berdasarkan tiga warna tersebut menjadi: 1) biru terang, 2) biru gelap, 3) biru dengan cincin coklat di sekitar pupil, 4) hijau, 5) hijau dengan cincin coklat di sekitar pupil, 6) bagian tengah cokelat dan bagian tepi hijau, 7) cokelat dengan beberapa hijau di bagian tepinya, 8) hijau terang, dan 9) hijau gelap.

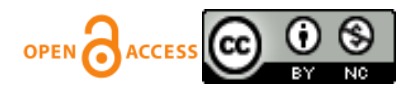


https://jurnal.unsulbar.ac.id/index.php/saintifik

Menurut (Tomar et al., 2018) Heterochromia Iridis dapat dikelompokkan ke dalam tiga tipe yaitu 1) complete heterochromia, apabila bola mata kanan berbeda warna dengan bola mata kiri, 2) central heterochromia, apabila bagian tengah bola mata berbeda warna dengan bagian tepi bola mata, dan 3) segmental heterochromia, apabila terdapat suatu segmen dari bola mata yang berbeda warna. Selain itu, (Gladstone, 1969) mengelompokkan Heterochromia Iridis berdasarkan fungsi mata, yang meliputi 1) Simple Heterochromia, dengan kedua mata yang berfungsi normal, 2) Complicated Heterochromia, dengan kedua mata tidak berfungsi normal dan terasosiasi dengan penyakit mata tertentu, dan 3) Sympathetic Heterochromia, dengan kedua mata yang tidak berfungsi karena adanya kerusakan pada saraf mata.

Heterochromia Iridis umumnya terjadi secara sporadis dan tidak terasosiasi dengan kelainan tertentu (syndrome). Akan tetapi, pada kasus yang langka, Heterochromia Iridis dapat menjadi bagian dari Waardenburg Syndrome, Sturge-Weber Syndrome, Parry-Romberg Syndrome, atau Horner's Syndrome (Genetic and Rare Disease Information Center, 2015).

Kasus mata dwiwarna atau Heterochromia Iridis ternyata dapat pula ditemukan di Indonesia, khususnya di Kecamatan Tinambung, Kabupaten Polewali Mandar. Ada satu anak laki-laki yang memiliki sifat "mata dwiwarna", yaitu mata sebelah kanan berwarna biru dan mata sebelah kiri berwarna coklat. Fenomena lokal ini penting untuk ditindaklanjuti agar bisa mengungkap karakteristik mata diwarna tersebut dan fenotip penyerta terkait mata dwiwarna. Penelitin ini menjadi penting dilakukan karena sampai saat ini belum ada laporan mengenai kasus mata dwiwarna di wilayah Sulawesi Barat. Hasil penelitian ini diharapkan dapat dijadikan dasar dalam penanganan fenomena lokal "mata dwiwarna" dan sebagai bahan dalam pembuatan media ajar kontekstual.

\section{METODE PENELITIAN}

Penelitian ini merupakan penelitian deskriptif kualitatif dengan desain penelitian studi kasus fenomena lokal mata dwiwarna di Tinambung, Polewali Mandar. Informan adalah individu dengan mata dwiwarna (Heterochromia Iridis). Data penelitian dikumpulkan melalui observasi dan wawancara.

Observasi dan wawancara dilakukan secara langsung dengan mengunjungi kediaman informan di Tinambung, Polewali Mandar. Aspek yang diamati selama observasi dan wawancara adalah: (1) warna mata, (2) fungsi mata, dan (3) fenotip penyerta. Analisis data menggunakan model analisis (Miles \& Huberman, 1994) meliputi reduksi data, penyajian data, dan penarikan kesimpulan.

\section{HASIL DAN PEMBAHASAN}

Hasil penelitian mengungkap dua kasus mata dwiwarna (Heterochromia Iridis) di Tinambung, Polewali Mandar sebagai berikut:

\section{Kasus I}

Seorang anak laki-laki berusia 5 tahun. Bungsu dari enam bersaudara. Memiliki mata kanan berwarna biru terang dan mata kiri berwarna coklat tua (Gambar 1). Karakter mata ini diperoleh sejak lahir. Hasil tes rabun menunjukkan fungsi mata normal. Hasil tes buta warna juga menunjukkan mata normal. Alis mata bersambung dengan rambut tipis pada bagian tengah (synophrys). Pangkal hidung lebar (broad nasal root) dan ujung hidung yang rata (flat nose tip). Ada bercak putih di bagian wajah pada pipi sebelah kanan dan jidat (skin hypopigmentation). 


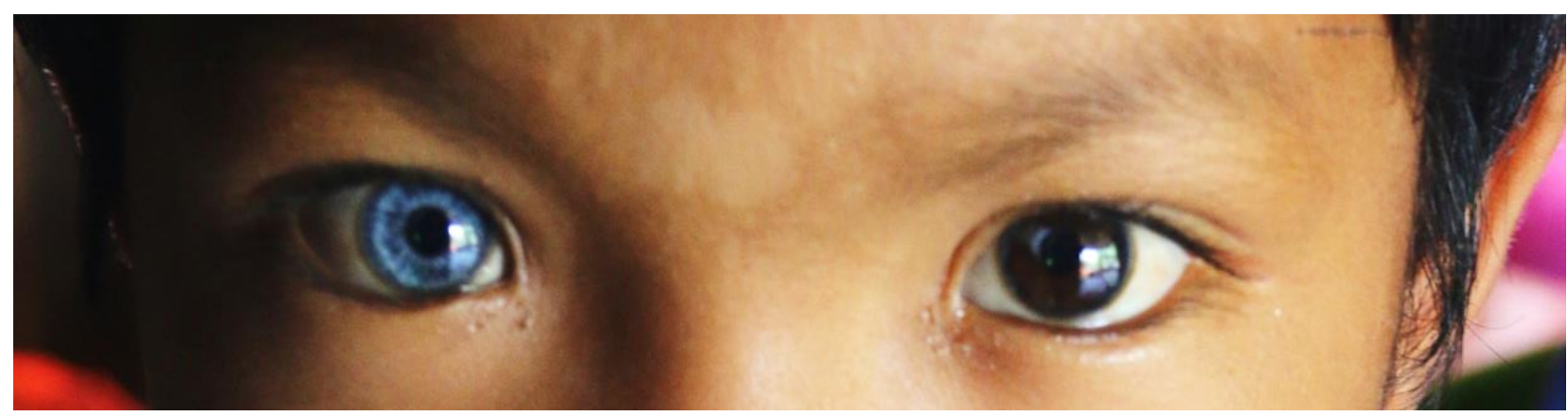

Gambar 1 Karakter mata dwiwarna, sebelah kanan biru dan sebelah kiri cokelat

\section{Kasus II}

Seorang wanita berusia 44 tahun. Anak keenam dari tujuh bersaudara. Memiliki mata berwarna coklat tua pada bagian tengah iris (inner ring) yang dikelilingi oleh warna biru pada bagian tepinya (outer ring) (Gambar 2). Karakter mata ini diperoleh sejak lahir. Hasil tes rabun menunjukkan fungsi mata normal. Hasil tes buta warna juga menunjukkan mata normal. Alis mata bersambung dengan rambut tipis pada bagian tengah (synophrys). Pangkal hidung lebar (broad nasal root) dan ujung hidung yang rata (flat nose tip). Terdapat gangguan pendengaran, namun minim, karena masih dapat berkomunikasi dengan baik. Gangguan pendengaran ini diperoleh sejak lahir. Rambut putih pada bagian tengah kepala yang muncul sebelum usia 30 tahun (premature gray hair).

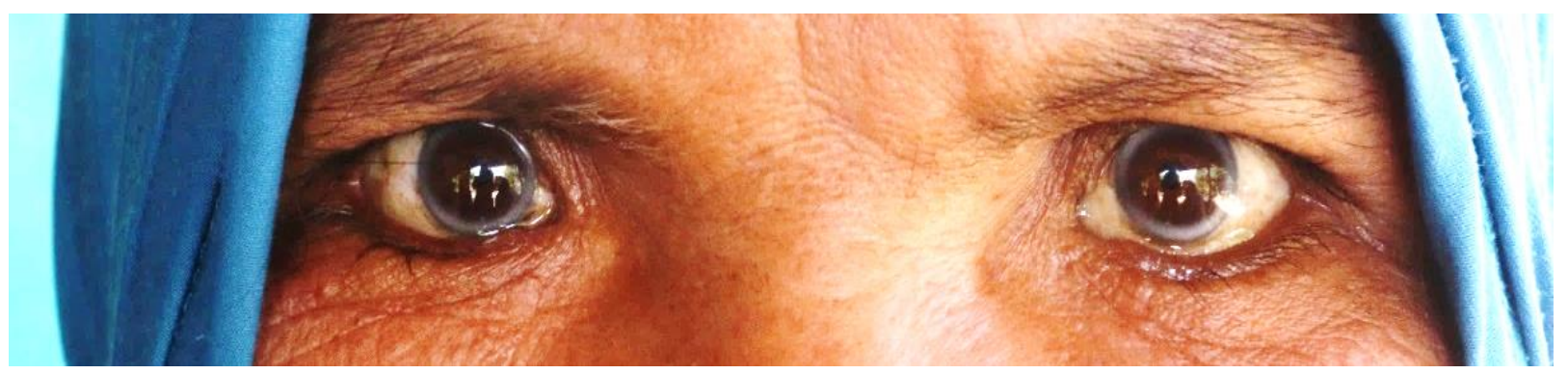

Gambar 2 Karakter mata dwiwarna, bagian tengah cokelat dan bagian tepi biru

Perbandingan karakteristik mata dan fenotip penyerta pada kasus I dan kasus II adalah sebagai berikut:

Tabel 1 Karakteristik mata dwiwarna pada kasus I dan kasus II

\begin{tabular}{|l|c|c|}
\hline \multicolumn{2}{|c|}{ Kasus I } & Kasus II \\
\hline Karakteristik mata & Biru terang & Bagian tengah cokelat, bagian tepi biru \\
\hline Warna mata kanan & Coklat tua & Bagian tengah cokelat, bagian tepi biru \\
\hline Warna mata kiri & Normal & Normal \\
\hline Tes rabun & Normal & Normal \\
\hline Tes buta warna & Ya & Ya \\
\hline Fenotip penyerta & Ya & Ya \\
\hline Alis mata bersambung & Ya & Tidak \\
\hline Pangkal hidung lebar & Ya & Ya \\
\hline Ujung hidung yang rata & Tidak & Ya \\
\hline Bercak putih pada kulit & Tidak & \\
\hline Gangguan pendengaran & &
\end{tabular}

Hasil penelitian karakteristik mata pada kasus I yaitu mata kanan berwarna biru terang dan mata kiri berwarna cokelat tua. Karakter mata dwiwarna ini sesuai dengan klasifikasi Heterochromia Iridis menurut (Tomar et al., 2018) yaitu apabila bola mata kanan berbeda warna dengan bola mata kiri, maka disebut tipe 
complete heterochromia. Sementara karakteristik mata pada kasus II yaitu bagian tengah mata berwarna cokelat dan bagian tepinya berwarna biru. Karakter mata dwiwarna ini juga sesuai dengan klasifikasi Heterochromia Iridis menurut (Tomar et al., 2018) yaitu apabila bagian tengah bola mata berbeda warna dengan bagian tepi bola mata, maka disebut tipe central heterochromia.

Tes buta warna (Ishihara's Test) dan tes rabun (Snellen's Test) pada kasus I dan kasus II menunjukkan hasil yang normal. Hal ini berarti bahwa kelainan pigmentasi iris pada kasus I dan kasus II tidak terasosiasi dengan penyakit mata tertentu dan tidak pula terkait dengan kerusakan saraf mata. Berdasarkan klasifikasi Heterochromia Iridis menurut (Gladstone, 1969), apabila kedua mata berfungsi normal, maka disebut tipe Simple Heterochromia.

Sejumlah fenotip penyerta yang ditemukan, baik pada kasus I maupun pada kasus II menunjukkan bahwa fenomena mata dwiwarna di Tinambung, Polewali Mandar terasosiasi dengan suatu sindrom. (Genetic and Rare Disease Information Center, 2015) mengatakan bahwa Heterochromia Iridis umumnya terjadi secara sporadic, namun pada kasus yang langka dapat terasosiasi dengan Sturge-Weber Syndrome, Parry-Romberg Syndrome, Horner's Syndrome atau Waardenburg Syndrome.

Karakter khas pada kasus Sturge-Weber Syndrome adalah tanda lahir di wajah yang menyerupai tumpahan anggur (port-wine stain), glaucoma yang terkadang disertai dengan Heterochromia Iridis, kejang, lemah otot, sakit kepala, dan retardasi mental. Sementara kasus Parry-Romberg Syndrome ditandai dengan penyusutan kulit dan jaringan lunak pada setengah sisi wajah, menciptakan bentuk wajah yang asimetris, permasalahan pada struktur mata. Heterochromia Iridis, kejang, migrain, rambut rontok, dan hiperpigmentasi. Kasus Horner's Syndrome ditandai dengan kelopak mata yang terkulai, pupil yang lebih kecil, Heterochromia Iridis, dan gangguan fungsi keringat pada bagian wajah. Adapun kasus Waardenburg Syndrome adalah Heterochromia Iridis, gangguan fungsi pendengaran, adanya rambut putih di atas dahi (jambul), bercak putih pada kulit, alis mata yang menyatu, pangkal hidung yang lebar, ujung hidung yang rata, dan rambut yang memutih pada usia muda (di bawah tiga puluh tahun) (Genetic and Rare Disease Information Center, 2015).

Berdasarkan pada informasi karakter khas yang dimiliki masing-masing syndrome yang terasosiasi dengan Heterochromia Iridis, maka dapat disimpulkan bahwa kasus mata dwiwarna di Tinambung Polewali Mandar merupakan Waardenburg Syndrome. Di Indonesia, kasus Waardenburg Syndrome pernah dilaporkan di wilayah Bandung sebanyak tiga kasus (Finisia et al., 2016). Satu kasus Waardenburg Syndrome di wilayah Jakarta juga pernah dilaporkan oleh (Zizlavsky et al., 2017). Adapun Lestari \& Prastyani (2020) juga pernah melaporkan satu kasus Waardenburg Syndrome di Surabaya. Sampai saat ini, peneliti belum menemukan adanya laporan kasus Waardenburg Syndrome di Wilayah Sulawesi Barat, khususnya Polewali Mandar.

Implikasi dari penelitian ini dapat dijadikan sebagai materi dalam pembuatan bahan ajar kontekstual khususnya di wilayah Sulawesi Barat, sehingga diharapkan dapat meningkatkan antusiasme dan motivasi belajar peserta didik. Selain itu, hasil penelitian ini juga bisa dijadikan dasar dalam penanganan fenomena lokal mata dwiwarna di Tinambung Polewali Mandar. Penanganan yang dapat dilakukan misalnya rehabilitasi pendengaran dengan penggunaan alat bantu dengar, hingga melakukan implan koklea pada kasus yang berat (Brookhouser, 1996). Konseling genetik juga perlu dilakukan pada keluarga mata dwiwarna di Tinambung Polewali Mandar agar mereka dapat memperkirakan kemungkinan munculnya kasus Waardenburg Syndrome pada keturunan mereka selanjutnya.

Penelitian ini merupakan penelitian awal, sehingga terdapat beberapa keterbatasan yang perlu dilakukan tindak lanjut. Pertama mengenai gangguan pendengaran pada kasus II, peneliti tidak melakukan pemeriksaan sensitivitas pendengaran menggunakan Free Field Test (FFT) atau Auditory Steady State Response Report (ASSR) untuk memperoleh data ambang dengar telinga. Kedua mengenai fenomena mata dwiwarna yang terasosiasi dengan Waardenburg Syndrome, ternyata meliputi tipe WS1, WS2, WS3, dan WS4. Data-data penelitian yang telah dikumpulkan belum cukup untuk menentukan fenomena mata dwiwarna di Tinambung Polewali Mandar termasuk tipe tertentu dari Waardenburg Syndrome.

\section{KESIMPULAN}

Karakteristik mata dwiwarna yang ditemukan di Tinambung Polewali Mandar ada dua kasus. Kasus I memiliki mata kanan yang berwarna biru terang dan mata kiri berwarna coklat tua, termasuk ke dalam tipe Complete Heterochromia. Kasus II memiliki mata yang bagian tengahnya berwarna coklat dan bagian tepinya berwarna biru, termasuk ke dalam tipe Central Heterochromia. Selain itu, mata dwiwarna yang ditemukan di 
https://jurnal.unsulbar.ac.id/index.php/saintifik

Tinambung Polewali Mandar, baik pada kasus I maupun pada kasus II tidak terasosiasi dengan penyakit mata tertentu dan tidak pula terkait dengan kerusakan saraf mata, sehingga termasuk tipe simple Heterochromia.

Fenotip penyerta yang ditemukan pada fenomena lokal mata dwiwarna di Tinambung Polewali Mandar yaitu alis mata bersambung, pangkal hidung lebar, ujung hidung yang rata, bercak putih pada kulit, gangguan pendengaran, dan rambut putih di usia muda. Fenotip penyerta tersebut menunjukkan bahwa fenomena mata dwiwarna di Tinambung Polewali Mandar terasosiasi dengan Waardenburg Syndrome.

Rekomendasi untuk peneliti selanjutnya yaitu lakukanlah pemeriksaan sensitivitas pendengaran menggunakan menggunakan Free Field Test (FFT) atau Auditory Steady State Response Report (ASSR) untuk memperoleh data ambang dengar telinga, khususnya pada kasus II, dan setelah mengenai tipe-tipe Waardenburg Syndrome yang sesuai dengan fenomena mata dwiwarna di Tinambung Polewali Mandar.

\section{DAFTAR PUSTAKA}

Andrew A. Dahl. (2020, July 21). Heterochromia Iridis. https://www.medicinenet.com/heterochromia_iridis/article.htm

Brookhouser, P. E. (1996). Sensorineural Hearing Loss In Children. Pediatric Otolaryngology, 43(6), 11951216.

Díez, C. M., Prado, S. R., \& Llaca, J. H. F. (2015). Segmental Pigmentation Disorder with Congenital Heterochromia Iridis. Open Journal of Pediatrics, 05(03), 213-217. https://doi.org/10.4236/ojped.2015.53032

Genetic and Rare Disease Information Center. (2015, April 8). Heterochromia iridis. https://rarediseases.info.nih.gov/diseases/8590/heterochromia-iridis

Gladstone, R. M. (1969). Development and Significance of Heterochromia of the Iris. Arch Neurol, 21, 184192. http://archneur.jamanetwork.com/

Lestari, A. Y., \& Prastyani, R. (2020). Case Report Waardenburg Syndrome Type I With Iris And Retinal Coloboma. Jurnal SainHealth, 4(1), 8-10.

Mackey, D. A., Wilkinson, C. H., Kearns, L. S., \& Hewitt, A. W. (2011). Classification of iris colour: Review and refinement of a classification schema. Clinical and Experimental Ophthalmology, 39(5), 462-471. https://doi.org/10.1111/j.1442-9071.2010.02487.x

Matthew B. Miles \& A. Michael Huberman. (1994). Qualitative Data Analysis: An Expanded Sourcebook. SAGE Publications.

Muiños Díaz, Y., Saornil, M. A., Almaraz, A., Muñoz-Moreno, M. F., García, C., \& Sanz, R. (2009). Iris color: validation of a new classification and distribution in a Spanish population-based sample. European Journal of Ophthalmology, 19(4), 686-689.

Tomar, M., Dhiman, R., Sharma, G., \& Yadav, N. (2018). Artistic iris: A case of congenital sectoral heterochromia iridis. Journal of Ophthalmic and Vision Research, 13(3), 359-360. https://doi.org/10.4103/jovr.jovr $91 \quad 17$

Wisudawan Finisia, F., Lasminingrum, L., \& Suseno, B. (2016). Gejala Klinis Sindroma Waardenburg Laporan Kasus. JSK, 2(2), 103-109.

Zizlavsky, S., Putri, S. T., \& Suwento, R. (2017). Gangguan pendengaran pada sindrom Waardenburg. ORLI, 47(2), 171-178. 